\title{
ORGANIZAÇÃO DO ESPAÇO PELA AGRICULTURA FAMILIAR: UM OLHAR MULTIFUNCIONAL SOBRE AS DINÂMICAS DO ASSENTAMENTO RURAL HORTO DE CAMAQUÃ - IPEÚNA/SP
}

Murilo Henrique Rodrigues de OLIVEIRA

Darlene Aparecida de Oliveira FERREIRA ${ }^{2}$

\section{Resumo}

O presente texto objetiva caracterizar as formas de organização social, econômica, cultural e natural do Assentamento Rural Horto de Camaquã, localizado no município de Ipeúna-SP. A análise de 38 lotes a luz da noção de multifuncionalidade possibilitou entender os preceitos e formas de atuação do assentado ativo, participante e colaborativo de práticas sociais, culturais, ambientais e econômicas de ajustamento coletivo e comunitário. Contudo, a partir deste trabalho foi possível qualificar positivamente a organização desta forma espacial a partir de uma lógica interna, ao defini-lo pela presença e não pela falta.

Palavras-chaves: Assentamento rural. Multifuncionalidade da agricultura. IpeúnaSP. Organização do espaço.

\section{Resumen}

\section{Organización del espacio por la agricultura familiar: una mirada multifuncional sobre las dinámicas del Asentamiento Rural Horto de Camaquã - Ipeúna/SP}

El presente texto objetiva caracterizar las formas de organización social, económica, cultural y natural del Asentamiento Rural Horto de Camaquã, ubicado en el municipio de Ipeúna-SP. El análisis de 38 lotes a la luz de la noción de multifuncionalidad posibilitó entender los preceptos y formas de actuación del asentado activo, participante y colaborativo de prácticas sociales, culturales, ambientales y económicas de ajuste colectivo y comunitario. Sin embargo, a partir de este trabajo fue posible calificar positivamente la organización de esta forma espacial a partir de una lógica interna, al definirlo por la presencia y no por la falta.

Palabras claves: Asentamiento rural. Multifuncionalidad de la agricultura. IpeúnaSP. Organización del espacio.

\footnotetext{
1 Graduando/Bolsista PIBIC CNPq - IGCE/UNESP Rio Claro; E-mail: mhrodriguesoliveira@hotmail.com

2 Professora Assistente Doutor do Departamento de Geografia - IGCE/UNESP Rio Claro; E-mail: darlene.ferreira@unesp.br
} 


\section{INTRODUÇÃO}

Considerando as assimetrias do espaço temos a estrutura fundiária brasileira assentada na grande propriedade, legitimada pela lógica capitalista de produção. Em face disto, a diversidade espacial revela a organização do espaço rural de acordo com os seus contextos regionais, inserindo novas dinâmicas que reescrevem o modo de vida no campo. Valendo-se dos pressupostos da noção de multifuncionalidade consideramos neste trabalho a análise de 38 lotes do Assentamento Rural Horto de Camaquã, localizado no município de Ipeúna-SP. Aos pressupostos desta noção é possível revisarmos as funções atribuídas historicamente à agricultura, através da reorientação dos termos teóricos e conceituais que cientificamente pensaram e analisaram as práticas agrícolas.

Partindo-se das contribuições de Carneiro (2003) a noção de multifuncionalidade amplia o olhar do investigador para questões antes não tidas como funcionais à agricultura, torna-se salutar o exercício de analisar as formas de organização do território, sob inscrição de determinados grupos que desenvolvem praticas socioespaciais, edificando novas formas espacialmente verificadas e, assim, revelam suas representações quanto às funções de determinados espaços.

O exercício por meio da aplicação da noção de multifuncionalidade permite ao investigador atribuir lógica para as formas organizativas analisadas, sobretudo por partir da análise das próprias dinâmicas das localidades consideradas. Assim, abre-se para discussão, quais funções são preenchidas e exercidas pela agricultura, para além da função eminentemente produtiva desta porção do território.

Diante destas considerações surgem questões que passam a orientar nosso debate a partir da análise das dinâmicas do processo de organização e gestão do território, recorte espacial considerado para este trabalho: em que medida a noção de multifuncionalidade orienta as atividades dos assentados? É possível identificarmos o caráter multifuncional do território circunscrito ao Assentamento? A multifuncionalidade no Assentamento é realidade ou se constitui possibilidade? Diante dos questionamentos a multifuncionalidade, muito mais do que ofertar um olhar técnico que qualifica (ou desqualifica) o Assentamento, configura-se como alternativa ao entendimento das diacronias presentes no espaço, e a partir do esclarecimento destas diferenças, possibilita a orientação de políticas públicas que de fato atendam as demandas e necessidades do grupo social em função da sua atuação sobre o território.

Com efeito, este trabalho intenta apresentar os resultados obtidos através da aplicação de formulários no Assentamento Rural Horto de Camaquã, localizado no limite dos municípios de Ipeúna e Rio Claro, onde o primeiro sedia majoritariamente o número de lotes. Cumpre esclarecer que, segundo dados do Instituto de Terras do Estado de São Paulo (ITESP, 2017), o Assentamento Rural Horto do Camaquã possui 47 lotes, dos quais 38 vertem para o município de Ipeúna e nove localizam-se dentro do limite do município contíguo já citado.

A explanação que se segue faz referência aos 38 lotes na porção Ipeunense. Ainda segunda a Fundação ITESP, o Assentamento está localizado na porção nordeste do município, somando uma área total de 1.372,41 hectares. Desta forma, intencionase a caracterização das formas de organização e gestão dos aspectos econômicos e socioculturais do Assentamento, a luz dos enfoques da noção de multifuncionalidade.

Deste ponto de vista, várias narrativas constroem a forma de assentamento na qual tivemos contato durante o levantamento dos dados primários. A partir de agora buscamos analisar a construção do projeto de assentamento a partir da análise do relatório técnico de avaliação de potencial da área, cedido pela Fundação Instituto de Terras do Estado de São Paulo "José Gomes da Silva" (ITESP), posteriormente apre- 
sentamos a discussão a respeito da aplicabilidade da noção de multifuncionalidade nos processos organizativos do recorte espacial considerado.

\section{ASSENTAMENTO RURAL HORTO DE CAMAQUÃ: A SUA CONSTRUÇÃO POR PARTE DO ESTADO E A REALIDADE EM CAMPO}

$\mathrm{Na}$ intenção de entendermos os processos que contribuíram (ou contribuem) para que o Assentamento se mostre como tal - expressando uma realidade comprometida do ponto de vista das condições de reprodução familiar - buscamos documentos que elencam as intenções do Estado para esta porção do espaço. O destaque dado a este agente, responde as narrativas que apontam as intervenções estatais como promotora de um processo de modernização que resulta na acentuação de diferenças e desigualdades sociais, por meio do caráter conservador e apaziguador dos conflitos no campo em favorecimento da grande propriedade (LEITE ; BARBOSA, 1991; BERGAMASCO; CARMO, 1991; BRUMER et. all, 1993; BARBOSA, 1994; WANDERLEY, 2011; MALAGODI, 2011).

Para a construção desta seção utilizamos o relatório técnico de avaliação potencial da área destinada aos planos de valorização de terras públicas do estado de São Paulo, previsto na lei de no 4.957/1985.

Em análise do período em que a lei supramencionada é instituída no estado de São Paulo, sob as diretrizes políticas do então governador Franco Montoro, (Barbosa; Leite, 1991) acentuam que em fins do governo militar, a política brasileira testemunha uma transição "na passagem do autoritarismo para democratização", onde a "reconstrução da legalidade do sistema de poder passava pela recriação de sua face ilegítima, ao mesmo tempo que avançava no caminho do Estado de Direito" (BARBOSA; LEITE, 1991, p. 41). Os autores ilustram em suas palavras um momento de reorientação política (em uma escala de análise a nível estadual) que virá a se preocupar com a questão agrária no estado, estabelecendo, por meio de uma política de "apaziguamento" com a intenção de evitar maiores conflitos - muito em função dos movimentos contrários a redemocratização do acesso à terra - uma política fundiária limitada ao reaproveitamento das terras públicas.

Este é o breve resgate do contexto de construção e implementação da lei $4.957 / 1985$, na qual, em seu texto alterado pela lei $16.115 / 2016$, atribui o dever aos planos públicos.

Artigo $2^{\circ}$ - Os planos públicos, a que se refere 0 artigo $1^{\circ}$ desta lei, deverão:

I - propiciar o aumento da produção agrícola, a instalação e elevação da produção agroindustrial e prestação de serviços ambientais;

II - propiciar ocupação estável, renda adequada e meios de desenvolvimento cultural e social a seus beneficiários;

III - assegurar a plena participação dos trabalhadores rurais, reunidos em sociedades civis de tipo associativo ou cooperativas, em todas as fases de sua elaboração e de sua execução;

IV - implantar, quando for o caso, assentamentos de trabaIhadores rurais em que os beneficiados pelos planos públicos poderão contar com os recursos disponíveis nos programas e ações voltadas para a reforma agrária e para o desenvolvimento da agricultura familiar. (ASSEMBLÉIA LEGISLATIVA DE SÃO PAULO, 1985) 
Pelo aparato institucional a legislação pertinente o planejamento, implantação, organização, gestão e desenvolvimento dos assentamentos rurais, provenientes dos planos de valorização de terras públicas que respondem ao dispositivo legal apresentado. Portanto, o que nos interessa nesta seção é a etapa de planejamento do Assentamento, em duas fases

Artigo $6^{\circ}$ - O planejamento será formulado para cada imóvel individualizadamente considerado, em duas fases:

I - elaboração de anteprojeto técnico, com definição de diretrizes básicas pela Fundação ITESP;

II - detalhamento do projeto consequente, com a contribuição dos beneficiários selecionados. (ASSEMBLÉIA LEGISLATIVA DE SÃO PAULO, 1985)

Para tanto, obtivemos acesso ao anteprojeto técnico, cedido pela Fundação ITESP, a qual descreve as potencialidades - já prevendo as deficiências - da área destinada a implantação do projeto de assentamento. O documento atesta a intenção institucional para a localidade considerada, em vias do discurso de promoção do desenvolvimento social e cultural dos beneficiários; discurso o qual não foi possível constatar empiricamente, dada a precariedade da efetiva seguridade desta intenção, frente à realidade encontrada.

O documento descreve de forma técnica os aspectos físicos da área, dos quais destacamos a textura arenosa do solo, com baixo teor nutricional abaixo da camada arável, agravado pela condição geomorfológica que confere a área feições de relevo movimentado - com inclinações variando de $12 \%$ a $20 \%$ - contribuindo para processos erosivos de grande monta, caso não sejam implantadas práticas adequadas (FUNDAÇÃO INSTITUTO DE TERRAS DO ESTADO DE SÃO PAULO - ITESP).

Segundo o mesmo órgão, em relação a cobertura vegetal, a área destinada ao projeto do assentamento permanecia ocupada com a monocultura de Eucalipto destinada à produção de dormentes para companhia Ferrovia Paulista S. A. (FEPASA). Atualmente, desta monocultura, encontra-se em alguns lotes a presença de tocos de Eucalipto que dificultam o plantio e a efetiva utilização das terras, restringindo-se a criação de animais de grande porte - bovinos (em alguns casos).

No que diz respeito à hidrografia, a área é cortada pelo Rio Cabeça, de fluxo perene - dada as condições climáticas da região - e ocorre a presença de nascentes e ribeirões (não identificados em nossa pesquisa). Apesar da boa disponibilidade hídrica, alguns lotes estão afastados das nascentes e dos fluxos superficiais, carecendo de bombeamento da água.

Quanto ao uso potencial da área, o relatório técnico indica 24 tipos de culturas, classificando-as de acordo com as suas restrições (levando em consideração somente as condições climáticas). Ao todo, durante o levantamento de campo, os assentados nos informaram a ocorrência de 37 tipos de culturas ${ }^{3}$, destacando-se a produção de banana, vendida ao Programa de Aquisição de Alimentos (PAA), à particulares (com a presença de mediadores), na cidade e região pelos próprios assentados, além do autoconsumo.

O que destacamos deste dado refere-se à diversidade da ocorrência de tipos de cultura, revelando o empenho dos agricultores em promover a função produtiva da terra e a ruptura da tendência de homogeneização da paisagem promovida pela monocultura; ademais, o encaminhamento da produção ao PAA possibilita a sensação

\footnotetext{
3 Este número total inclui aquelas culturas que ocorrem ao menos em uma unidade, seja ela para consumo ou para fins mercantis.
} 
de maior segurança de rendimentos, já que o "cliente" é o próprio governo; por conseguinte, as vendas na cidade ou na região constituem alternativa ao produtor, por meio do estabelecimento de um circuito curto, mesmo que de forma esporádica, e por fim o autoconsumo como expressão de autonomia e segurança alimentar das famílias assentadas.

Ao exposto até o momento destacamos que a inserção dos assentados nas dinâmicas produtivas do município reafirmam a sua presença no contexto socioeconômico do local, justificando a luta pelo acesso à terra e, assim, contribuindo para a construção e a afirmação da figura do assentado como sujeito produtivo. A premência deste destaque, encontra-se nas contribuições de Cardoso, Flexor ; Maluf (2003), que chamam a atenção para a inserção do assentado em um contexto "sócioinstitucional" por meio do acesso à terra; partindo-se do acesso, tem-se a possibilidade de "fazer a terra produzir" e, por meio da organização familiar, gerenciam as formas de produção com maior autonomia, o que permite as famílias assentadas criarem os seus próprios "mercados" e ao criar estes "mercados" reafirmam a sua imagem e a sua identidade.

Por conseguinte, o relatório técnico de avaliação potencial da área, descreve em vários momentos as restrições e dificuldades que os assentados encontrariam quando do acesso aos lotes. Não podemos atestar para esta área o esgotamento da fertilidade do solo como principal fator limitante às práticas produtivas. O relevo acidentado, a presença dos tocos de eucalipto (atualmente) e para alguns lotes a limitação no acesso a água configuram os principais fatores limitantes à produção. Entretanto, o relatório governamental assume as limitações do fator relevo e prevê alternativas quanto ao uso e possível prática produtiva a ser exercida em determinados lotes - cumpre esclarecer que os assentados nestas situações são obrigados a se adaptar e até mesmo transformar os seus hábitos de produção em função das limitações do terreno.

Em suma, o documento constrói a figura de um agricultor familiar interessado eminentemente na produção agropecuária, sem grandes variações no tocante da produção, direcionando-o à culturas com maior segurança de viabilidade econômica e, portanto, de escoamento mercantil. Atenta à construção de uma imagem ideal de agricultor familiar veiculadas pelas políticas públicas.

Wanderley (2003) atesta que o título familiar descreve aquele agricultor que inscreve o núcleo familiar nos compromissos da propriedade, no que diz respeito a sua capacidade de produção, em função do trabalho e gestão do empreendimento. Desta forma, o agricultor familiar pretendido pelas políticas de apoio que atendem a agricultura familiar ${ }^{4}$ é caracterizado por aquele que consiga inserir-se no mercado por meio da obtenção e utilização de tecnologias modernas, tidas como produtivas; aquele em que a maior parcela da renda da família seja expressa pela atividade produtiva da agropecuária; e por fim, o perfil monoativo do agricultor (WANDERLEY, 2003).

Ao exposto, na intenção de concluir esta seção, identificamos estas intenções cristalizadas no documento, por meio de indicações de técnicas como irrigação, rotação de pastagem, terraceamento e até mesmo a indicação ao não uso de agrotóxicos (o que para alguns é descartado sobre a justificativa da onerosidade da produção orgânica, muito em função do baixo conhecimento técnico).

A exigência de conhecimento e domínio de técnicas por parte dos assentados, os quais podem não ter capital suficiente (seja capital financeiro ou cultural) para

\footnotetext{
${ }^{4}$ A autora destaca principalmente o PRONAF para exemplificar e justificar as suas colocações, o que nos interessa diretamente, já que alguns assentados alegaram possuir financiamento ligado ao programa de apoio a agricultura familiar e passam a responder e se enquadrarem aos moldes do programa.
} 
implantar e manter tais práticas ${ }^{5}$ reverbera no discurso das limitações da propriedade da terra em um contexto de reforma agrária. Valverde (1980), afirma que "se as condições de mercado, o capital e os conhecimentos agrícolas do lavrador não permitirem o emprego de tais sistemas intensivos, o lote pequeno será a maneira mais rápida de reduzi-lo à miséria" (VALVERDE, 1980, p. 62).

\section{A NOÇÃo DE MULTIFUNCIONALIDADE NA LEITURA E ANÁLISE DO ASSENTAMENTO RURAL HORTO DE CAMAQUÃ: APONTAMENTOS SOBRE A OCORRÊNCIA OU NÃO A PARTIR DA REALIDADE ENCONTRADA}

Ao observarmos que, apesar das discussões a respeito da multifuncionalidade serem marcadas por demandas sociais que revisam as funções e, consequentemente, as práticas tipicamente agrícolas, está também registra uma reorientação social à práticas de equacionamento de dinâmicas e processos socioambientais. Em virtude desta análise, nos intencionamos a pensar que, a luta pelo acesso à terra, pode indicar importantes contribuições para o desenvolvimento efetivo de práticas multifuncionais na agricultura. Ao representar uma alternativa de produção e de modo de vida, o assentamento rural, encontra em sua base organizativa, o resgate e a reconexão com práticas tradicionais que historicamente promovem, conservam e garantem a produção, seja ela de caráter mercantil ou de subsistência.

Em rápida revisão das funções da terra, atribuída pelo Estatuto da Terra promulgado em 1964, durante os arranjos do governo militar, é possível encontrarmos orientações jurídicas nos "moldes" da noção de multifuncionalidade, quando do registro das funções deste recurso natural

Art. $2^{\circ}$ É assegurada a todos a oportunidade de acesso à propriedade da terra, condicionada pela sua função social, na forma prevista nesta Lei.

$\S 1^{\circ}$ A propriedade da terra desempenha integralmente a sua função social quando, simultaneamente:

a) favorece o bem-estar dos proprietários e dos trabalhadores que nela labutam, assim como de suas famílias;

b) mantém níveis satisfatórios de produtividade;

c) assegura a conservação dos recursos naturais;

d) observa as disposições legais que regulam as justas relações de trabalho entre os que a possuem e a cultivem. (BRASIL, 1964, grifo nosso)

Resultado da pressão exercida pelos camponeses em intenso processo de proletarização, o Estatuto da Terra pode ser entendido como um importante passo com "aval" governamental - em direção a uma nova proposta de estruturação do campo brasileiro. Este próprio movimento pelo acesso, demonstra a importância de se considerar uma nova configuração social na reorganização da estrutura fundiária no Brasil. Nesta perspectiva, o movimento social de luta por acesso à terra é anunciado como uma "outra configuração social possível", conforme acentua Porto-Gonçalves (2006), a qual indica que o rural não se constitui (ao menos não mais) como

\footnotetext{
5 Quanto a rotação de pastagens (e o domínio de técnicas em geral) entra em debate o tamanho do lote e os impactos que a intensidade da atividade pode causar a condição socioeconômica nas famílias assentadas.
} 
espaço exclusivo a produção de alimentos, mas com tributários a preservação ambiental, manutenção tradições culturais e local de vivência. Existe, desta forma, um grupo social que busca acesso à terra e, no limite do discurso, tenta romper com o projeto de agricultura pensado para o Brasil: produção de commodities.

Deste modo, a forma de assentamento rural, expressa um local de vivências, com intenso trânsito de informações, formações e histórias que escrevem uma nova perspectiva de espaço rural, com vistas à estabilidade e autonomia produtiva por meio da obtenção, gestão e organização de seus lotes. Assim, indicando um dos preceitos da multifuncionalidade que aponta como função da agricultura a manutenção das tradições culturais, o envolvimento com as práticas agrícolas por meio da sociabilidade dos indivíduos, pode acabar por possibilitar uma maior conexão com a terra e desencadear processos de reconhecimento por parte dos assentados como agricultores (ou produtores rurais), orientando práticas produtivas que promovem 0 desenvolvimento dos lotes e do assentamento.

Carneiro e Maluf (2003) analisam as funções da agricultura familiar centrados, principalmente, em quatro dimensões básicas da multifuncionalidade, a saber: a reprodução socioeconômica das famílias, a partir da composição e das fontes geradoras de renda; as condições de permanência no campo e as práticas de sociabilidade; a promoção da segurança alimentar da sociedade e das próprias famílias rurais, abrangendo a produção para o autoconsumo e para a comercialização; a manutenção do tecido sociocultural, se referindo as condições de vida e da reprodução das culturas locais; a preservação dos recursos naturais e da paisagem rural, aqui entendido como referência ao uso de recursos e sua preservação. Em todas as dimensões apresentadas há a valorização das características dos lugares.

Ao esforço reflexivo e teórico, voltamos ao assentamento em análise para os apontamentos a respeito da noção aqui assumida. Iniciamos pelas atividades desenvolvidas nos lotes, como expressão das estratégias encontradas pelas famílias para garantir a manutenção e reprodução familiar. Notou-se como atividade agrícola expressiva nos lotes a produção de banana (ocorre em 28 lotes), produção que encontra, como dissemos, escoamento através do Programa de Aquisição de Alimentos (PAA), na grande maioria dos lotes. Podemos justificar a opção por esta cultura pela fácil comercialização quando da constituição de circuitos curtos (tais como, feiras de produtores ou vendas na cidade de porta em porta), indicando o anseio por estabilidade e garantias de rendimento. A pecuária para produção de leite ocorre em 19 lotes, constituindo-se uma atividade coadjuvante ao autoconsumo e a produção de queijo, atividade que possibilita agregação de valor às famílias.

Como já foi apresentado anteriormente registrou-se a ocorrência de 37 tipos de culturas nos lotes do Assentamento, sendo que deste total 15 são frutas e 9 são legumes (os demais dividem-se entre grãos, oleaginosas e gramíneas - como a cana de açúcar). Diante destes dados somos vertidos a pensar que a produção de alimentos nos lotes possui um forte viés de autoconsumo - salvo algumas exceções com caráter mercantil, as quais desenvolveremos a análise posteriormente -, com a presença de culturas de milho e de cana destinadas a produção de ração para o trato de aves, bovinos e suínos. Entre a produção animal, a criação de porcos é a que registrou maior ocorrência (presente em 27 lotes), seguido da criação de frangos (26 lotes); a opção por estas criações também indicam um opção pela garantia do autoconsumo, por meio de atividades que se constituem "fáceis" do ponto de vista do cuidado e de uma possível situação de venda para sanar algum compromisso financeiro da família.

Em virtude do exposto, a tendência a culturas que oferecem maiores seguranças do ponto de vista do autoconsumo e eventual mercantilização, confirma a discussão de Maluf (2003, p. 142), em que o autor conclui que "o peso da produção do 
autoconsumo, como garantia da segurança alimentar das famílias rurais viu-se em face da limitada renda monetária propiciada pelo componente mercantil da atividade agrícola própria $[\ldots] "$..

Considerando a observação do autor, o cenário encontrado no tocante da produção, somado aos rendimentos mensais dos núcleos familiares - onde 19 lotes possuem renda mensal entre dois e três salários mínimos, 13 com renda mensal de até um salário mínimo e dois com renda entre três e cinco salários mínimos; sendo que dos 38 lotes, 20 nos informaram que algum membro da família recebe aposentadoria - identificamos a dificuldade de estabelecimento do componente mercantil da produção como elemento que assegure a reprodução socioeconômica das famílias.

Em resposta ao esvaziamento da produção agrícola como elemento definidor de reprodução socioeconômica das famílias, identificamos atividades fora dos lotes ou não-agrícolas como estratégia de elevação da renda familiar. Em 16 lotes ocorrem o envolvimento de algum membro da família com estas atividades, em sua grande maioria constituem-se jovens entre 15 e 29 anos, que alegam utilizar seus rendimentos em benefício próprio. Apesar desta informação revelar a não utilização destes rendimentos em favor e benefício do núcleo familiar, tal ocorrência corrobora as observações de Carneiro (2007) e Malagodi; Marques (2007) que analisaram jovens a partir das suas trajetórias de vida e chegam a conclusão que estes são orientados, muitas vezes, por um projeto de vida que entende a renda monetária própria e individual como possibilidade de autonomia.

Diante do exposto, a figura dos jovens - entendidos como categoria social compreendida na faixa de idade de 15 a 29 anos - expressa demasiada importância nas estratégias familiares do Assentamento. Diante dos resultados foi possível identificar quatro tipos de lotes, em função da diversidade de culturas, função mercantil e autoconsumo da produção, idade dos assentados e a adesão a técnicas de manejo e produção. Assim, as quatro classes em que os lotes se apresentaram são: a) lotes com função mercantil e a presença de jovens e assentados menores de 60 anos; b) lotes com função mercantil e assentados com mais de 60 anos; c) lotes com função de autoconsumo e algum membro familiar envolvido em atividade não agrícola; d) lotes com função de autoconsumo não registrando envolvimento com atividade não agrícola.

Por meio desta classificação, 26 lotes apresentaram a função mercantil ${ }^{6} \mathrm{com}$ a presença de jovens e assentados menores de 60 anos, apresentando grande diversidade produtiva, declarando ao menos uma cultura ou criação com função mercantil, valendo-se de técnicas de manejo e produção que ofertam maiores garantias produtivas. Desta parcela de lotes, em 18 foram registrados a permanência de jovens entre a faixa de idade apontada neste relatório, em 4 a presença de criança na faixa dos 5 aos 15 anos. Assim, diante do qualitativo de lotes com maior diversidade produtiva, estes lotes com a presença de sujeitos de menor idade, revelam a importância desta categoria social nas estratégias produtivas e reprodutivas das famílias.

A importância de se atentar ao papel jovem no contexto do assentamento em análise - e até mesmo nas discussões sobre o modo de vida rural -, parte da perspectiva de continuidade histórica do rural que, por meio da dinâmica e sucessão geracional atribui às relações familiares o exercício de transmissão e sucessão dos hábitos de produção familiar, bem como, a conservação do patrimônio desta instituição (CAR-

\footnotetext{
${ }^{6}$ Cumpre esclarecer que anteriormente destacamos a função de consumo como elemento definidor da produção no Assentamento, porém, a maior parcela apresenta algum elemento de produção mercantil; o que parece uma contradição dentro das nossas análises será melhor esclarecida adiante com a dedução dos qualitativos socioeconômicos que acabará por reduzir a apenas oito (8) lotes a função mercantil (conforme expresso na tabela 1 ).
} 
NEIRO, 2007; MALAGODI ; MARQUES, 2007; KUMMER ; COLOGNESE, 2013). Ao jovem, direciona-se as intenções, projetos e dificuldades do núcleo familiar, que passam a contrastar com os projetos de vida de jovens rurais inseridos nas dinâmicas, costumes e demandas de uma sociedade moderna e globalizada.

Ainda sobre o exame quantitativo do primeiro grupo analisado em que se destaca a presença de jovens, notou-se que este grupo apresentou os maiores níveis de renda mensal, a demonstrar que dos 26 lotes pertencentes a este grupo, 16 possuem renda entre dois e três salários mínimos e 2 (dois) possuem renda entre três e cinco salários mínimos - os demais indicaram receber até um salário mínimo. Entretanto, na intenção de mensurarmos o número de lotes que organizam e estruturam sua renda estritamente em função da atividade agrícola, deduzimos do total destes 26 lotes, aqueles em que algum membro desenvolve atividade não agrícola, bem como, o recebimento de benefícios da previdência social, assim, somente 7 (sete) lotes, valem-se da renda proveniente da produção para manutenção e reprodução socioeconômica da família. Tal observação corrobora a afirmação de Maluf (2006), na qual o autor registra que "quanto mais elevado o nível de renda familiar, menor a participação relativa dos ingressos monetários provenientes desta última atividade [produção agrícola mercantil]" (MALUF, 2003, p. 138).

A tabela 1 sintetiza as informações até aqui consideradas para todos os grupos anteriormente indicados.

Ao exposto, a tabela 1 nos apresenta um cenário que indica a baixa participação da atividade agrícola na estruturação da renda mensal dos lotes em análise, somando apenas 8 (oito) lotes - o que representa $21,05 \%$ - no conjunto considerado. A díspar, a ocorrência de atividades não-agrícolas e o recebimento de benefícios da previdência social, favorece a renda de 29 lotes, o que representa cerca de 76,31\% do total.

Deste cenário é necessário nos atentarmos para o baixo rendimento ofertado pela mercantilização dos produtos agrícolas, bem como, os apontamentos da onerosidade do processo produtivo no campo - como já debatidos por diversos autores que se ocuparam em pensar as dinâmicas do rural (CARNEIRO; MALUF, 2003; CARNEIRO, 2006; MALAGODI, 2011). Entretanto, para além dos aspectos que envolvem a análise econômica da composição dos lotes, é de extrema validade a consideração deste aspecto como uma estratégia dos grupos familiares, o que se reveste na literatura pelo entendimento da pluriatividade.

Salvo o debate teórico conceitual entorno da noção de pluriatividade - harmoniosamente revisado por Carneiro (2006)7- este orienta um novo modo de organização das atividades econômicas dos agricultores, por meio de atividades alternativas que favorecem o acesso destes sujeitos ao mercado de trabalho (CARNEIRO, 2006 Apud SCHNEIDER, 2005). A renda proveniente desta estratégia, viabiliza e, por vezes, promove a manutenção das práticas agrícolas, por meio de uma maior autonomia dos caracteres produtivos, muitas vezes possível através do "autofinanciamento" da produção com a utilização de parte desta renda em benefício da lavoura (CARNEIRO, 2006).

\footnotetext{
7 Ver mais em: CARNEIRO, M. J. Pluriatividade da agricultura no Brasil: uma reflexão crítica. In. SCHNEIDER, S. (orgs.). A diversidade da agricultura familiar. Porto Alegre: Editora da UFRGS, 2006. pp. $165-185$
} 
Tabela 1 - Grupo de lotes e

fonte de renda

\begin{tabular}{|c|c|c|c|c|c|c|c|c|}
\hline \multirow[b]{2}{*}{$\begin{array}{l}\text { Grupos de } \\
\text { lotes }\end{array}$} & \multirow[b]{2}{*}{$\begin{array}{l}\text { No de } \\
\text { lotes }\end{array}$} & \multicolumn{4}{|c|}{ Renda mensal } & \multirow[b]{2}{*}{$\begin{array}{l}\text { Benefício } \\
\text { da } \\
\text { previdência } \\
\text { social }\end{array}$} & \multirow[b]{2}{*}{$\begin{array}{l}\text { Atividades } \\
\text { não } \\
\text { agrícolas }\end{array}$} & \multirow{2}{*}{$\begin{array}{c}\mathrm{N}^{\circ} \text { de lotes } \\
\text { com renda } \\
\text { proveniente } \\
\text { somente da } \\
\text { atividade } \\
\text { agrícola }\end{array}$} \\
\hline & & $\begin{array}{l}\text { Até } \\
1 \\
\text { S. } \\
\text { M. }\end{array}$ & $\begin{array}{l}\text { De } \\
2 \mathrm{a} \\
3 \mathrm{~S} . \\
\mathrm{M} .\end{array}$ & $\begin{array}{l}\text { De } \\
3 \text { a } \\
5 \mathrm{~S} . \\
\text { M. }\end{array}$ & $\begin{array}{c}\text { Não } \\
\text { soube } \\
\text { responder }\end{array}$ & & & \\
\hline $\begin{array}{l}\text { a) função } \\
\text { mercantil com } \\
\text { a presença de } \\
\text { jovens e } \\
\text { assentados } \\
\text { menores de } 60 \\
\text { anos }\end{array}$ & 26 & 8 & 16 & 2 & 0 & 10 & 14 & 7 \\
\hline $\begin{array}{l}\text { b) função } \\
\text { mercantil com } \\
\text { assentados } \\
\text { com mais de } \\
60 \text { anos }\end{array}$ & 6 & 4 & 1 & 0 & 1 & 3 & 1 & 1 \\
\hline $\begin{array}{l}\text { c) função de } \\
\text { consumo com } \\
\text { algum membro } \\
\text { envolvido em } \\
\text { alguma } \\
\text { atividade não- } \\
\text { agrícola }\end{array}$ & 3 & 1 & 1 & 0 & 1 & 2 & 1 & 0 \\
\hline $\begin{array}{l}\text { d) função de } \\
\text { consumo não } \\
\text { registrando } \\
\text { envolvimento } \\
\text { com atividade } \\
\text { não-agrícola }\end{array}$ & 2 & 0 & 1 & 0 & 1 & 1 & 0 & 0 \\
\hline
\end{tabular}

Fonte: Trabalho de campo - Abril e Maio de 2017

Deste modo, o debate sobre a pluriatividade do agricultor - e até mesmo do núcleo familiar - enseja a discussão a respeito de um novo modo de vida rural, em que o agricultor ou algum membro de sua família aciona outros nichos de mercado como forma de entrada ao mercado de trabalho, com vistas a garantia de rendimentos dado o conjunto da função produtiva do espaço rural, marcado pelo baixo retorno e a onerosidade do trabalho. Carneiro (2006), nos lembra que a pluriatividade nem sempre se reveste na função de promotora da atividade agrícola, ela marca uma "relação plural" com o trabalho.

No âmbito do Assentamento, as atividades não agrícolas são realizadas, na grande maioria, pelas esposas ou filhos dos produtores assentados, sobretudo alegando investir os rendimentos no consumo individual. Além de indicar à análise, a baixa participação da atividade agrícola na estruturação do lote como unidade produtiva, esta observância ao papel "pluriativo" de alguns assentados apresenta novamente uma ruptura do padrão monoativo proposto pelo estado, através de uma pers- 
pectiva de agricultura que atribui sucesso ao agricultor de função empreendedora e competitiva, conforme acentuam Wanderley (2003) e Carneiro (2006).

Portanto, ao passo que os dados revelam um certo "fracasso" produtivo em função das formas como os lotes são pensados e incentivados a se reproduzir socioeconomicamente, o olhar multifuncional nos atenta a uma determinada lógica que edifica as relações com a terra, o trabalho e até mesmo o próprio capital em face as práticas desenvolvidas interna e externamente ao lote. Neste sentido, direcionamos nossa atenção para condições que viabilizam a atividade agrícola favorecendo economicamente determinado grupo de assentados, através da mercantilização dos produtos.

Como já elencado anteriormente, o grupo que conjuga a função mercantil, presença de jovens e maior diversidade produtiva, apresenta os maiores rendimentos do ponto vista da produção (grupo "a" - 26 lotes). Porém, ao passo que os lotes deste grupo conseguem otimizar a produção, a faz comprometidos com um pacote quimicamente dependente, sobretudo no uso de fungicida e herbicidas - 17 lotes fazem uso de agrotóxicos na produção. Inversamente, os lotes que atribuem a produção ao autoconsumo, indicaram não fazer uso de agrotóxicos, o que nos indica a função de garantia da soberania e segurança alimentar.

No tocante da segurança alimentar notou-se que os lotes funcionais à mercantilização, apresentaram maior dependência nas compras de alimentos em supermercados. Assim, dos grupos "a" e "b", 21 lotes apresentaram de alto à médio consumo de produtos provenientes "da cidade", em face de 11 lotes com baixo consumo, elencando apenas produtos da cesta básica como provenientes do mercado: arroz, feijão e farinhas. Ainda, todos os 3 (três) lotes do grupo "c", caracterizado pelo autoconsumo e com membros da família envolvidos em atividades não-agrícolas apresentaram alto consumo de produtos advindos da compra em supermercados, majoritariamente com a exceção de verduras e legumes. Por fim, no grupo " $d$ " (autoconsumo com nenhum membro em atividades não agrícolas), registrou um padrão de médio a baixo consumo.

Contudo, é patente a observação de que em algum grau, as atividades nãoagrícolas, ao passo que incrementam a renda mensal da família, orientam a um padrão de consumo tipicamente urbano, com forte dependência de produtos industrializados. A premência desta observação, encontra-se no discurso das novas ruralidades ou da ruralidade contemporânea, que identifica esta relação plural do trabalho no campo, como fortes incrustações do urbano sobre o rural ${ }^{8}$.

Por fim, na análise da preservação do meio ambiente notou-se demasiada incoerência entre o discurso e a prática. Em entrevista, 33 lotes afirmaram realizar a manutenção dos recursos hídricos e vegetação, em face de 5 (cinco) lotes que não realizam tal manutenção, porém 21 lotes fazem uso de agrotóxicos, o que demonstra uma visão pouco comprometida e incipiente de preservação, sobretudo elencando como técnica de manutenção e preservação o fato "não mexer" nessas áreas.

No uso de agrotóxico não há o entendimento, por parte dos assentados, dos impactos nas áreas em torno das áreas de aplicação, podendo favorecer a queda da diversidade, somada à contaminação dos recursos hídricos; quanto à pecuária, os impactos são registrados no pisoteio da vegetação (quando esta área não está cerca-

\footnotetext{
8 Sobre essas considerações ver: Carneiro (2011) que ao discutir o papel do jovem no modo de vida rural, resgata considerações a respeito da relação rural/urbano. A mesma autora, em 2006, ao discutir a pluriatividade, considera a vertente que trata desta noção em função dos "transbordamentos do urbano sobre rural", a partir da visão de Silva (1999) do "Novo Rural". Sacco dos Anjos; Caldas (2006), também fazem referências ao "rurbano" para tratar da pluriatividade e sucessão hereditária.
} 
da) em função do acesso aos córregos e rios parar beber água, o que favorece também, a erosão e o consequente processo de assoreamento destes corpos hídricos.

Diante do todo exposto somos vertidos a pensar que a noção de multifuncionalidade da agricultura não orienta as práticas socioespaciais do Assentamento Rural Horto de Camaquã, porém configura-se como possibilidade para a atuação e favorecimento da classe assentada. Ao nos basearmos na ideia de que a noção de multifuncionalidade revisa as funções tipicamente atribuídas ao rural, podemos agregar ao debate a promoção de novas formas de relação deste espaço com a sociedade. Essas novas formas de relação entre atividade agrícola e sociedade permitem a consolidação e a reafirmação do papel do agricultor no tecido social, enquanto sujeito ativo nas dinâmicas sociais, econômicas, culturais e ambientais que produzem e reproduzem o espaço.

Ao lançarmos o olhar multifuncional sobre o Assentamento e identificarmos as possibilidades que a noção aqui assumida apresenta às estratégias dos assentados, estamos - para além de anunciar novas e melhores configurações socioespaciais, admitindo restrições que obstaculizam o seu desenvolvimento - em busca de um melhor equacionamento social, ambiental, econômico e político desta parcela da população em função do seu contexto de inserção.

\section{CONSIDERAÇÕES FINAIS}

Nesta composição, assumimos a ideia de assentamento rural como espaço de reconstrução social, local de vivências, de possiblidades, bem como, uma alternativa à gestão e organização do território, resultado, na maioria das vezes, de dinâmicas externas a sua conformação. Com este entendimento, construímos as análises aqui apresentadas, vertidos a pensar o Assentamento Rural Horto de Camaquã a partir do exame de sua própria dinâmica, localizando-o em um espaço abstrato - caracterizado pelas interações e relações estabelecidas por esta forma espacial - a partir da inscrição do assentamento na dinâmica local e regional.

Ao considerarmos o Assentamento através dos caracteres que o definem e o redefinem, possibilitou-se a elucidação de características que por ora permitiu a sua implantação, mas que o desenvolve com algumas limitações. Limitações estas que os assentados/produtores devem lidar todos os dias, em busca da manutenção do seu conjunto familiar.

Em função disto, este trabalho se esforçou para além da observância dos aspectos produtivos - o que em parte se explica pela escolha da noção de multifuncionalidade para o exame pretendido -, ao considerar conjuntamente as intenções governamentais e as influências do contexto em que o Assentamento está inserido, com vistas à compreensão do significado destes fatores na dinâmica e nas relações desenvolvidas no interior desta forma de gestão do território. Como já expresso em linhas anteriores deste trabalho o olhar multifuncional engendrou a superação do entendimento das funções tipicamente atribuídas à agricultura, o que nos possibilitou o esclarecimento das estratégias de reprodução socioeconômica e até mesmo cultural dos assentados.

Deste modo, a escolha dos preceitos da multifuncionalidade favoreceu o olhar pormenorizado das dinâmicas internas do Assentamento, sem deixar de considerar o seu entorno, para sua posterior qualificação. Por meio deste exame, os pressupostos da noção aqui considerada suscitaram conclusões que dizem respeito às estratégias familiares e a reprodução socioeconômica e cultural deste grupo e, no limite da curi- 
osidade científica que instigou o aprofundamento do entendimento das demais funções atribuídas pela orientação teórica conceitual escolhida, a citar: preservação da paisagem rural e construção/reconstrução de identidades sociais. Contudo, a partir deste trabalho foi possível qualificar positivamente a organização do Assentamento "preenchendo-o" de uma lógica interna, definindo-o pela presença e não pela falta.

Elementos como acesso à terra, a busca pela posse jurídica do lote e a luta por permanência através de estratégias de reprodução socioeconômicas dos grupos familiares - estruturados pelo trabalho agrícola e não agrícola, bem como, a função do lote como espaço de morada - são elementos que estruturam os processos e dinâmicas do Assentamento Rural Horto de Camaquã. A premência desta conclusão parte do exame de que o acesso à terra, nos moldes verificados no campo brasileiro, não garante a permanência destes grupos sociais nas terras destinadas aos projetos de assentamentos. Como verificado durante o levantamento bibliográfico que norteou esta análise, a instabilidade política e governamental, no que diz respeito aos programas e políticas públicas que assistem esta parcela da população, são reconhecidamente verticais, burocráticos, instáveis e promotoras de insegurança ao desenvolvimento e permanência dos assentados nos lotes.

Ao exposto, vimos que os assentados dispõem de estratégias de reprodução familiar, sobretudo ancorados no desenvolvimento de atividades não agrícolas em virtude de restrições físicas e sociais presente no Assentamento Horto de Camaquã, já previsto nos estudos realizados pelo órgão estadual aqui considerado. Estas restrições em conjunção com as visões de mundo dos assentados que, em sua grande maioria, vê na luta pelo acesso à terra uma possibilidade de autonomia e alternativa de modo de vida, atribui ao lote, em primeira instância, a função de morada. Em consonância a este exame, destacamos a figura do jovem como um agente importante do ponto de vista produtivo e de garantias de continuidade histórica do rural e, especificamente no nosso caso, do lote.

A multifuncionalidade permitiu novos olhares e ampliou as experiências, conduzindo as análises aqui enunciadas. Porém, ávidos a responder as questões que orientaram este trabalho - Em que medida a noção de multifuncionalidade orientam as atividades dos assentados? É possível identificarmos o caráter multifuncional do território circunscrito ao Assentamento? A multifuncionalidade no Assentamento é realidade ou se constitui possibilidade? - concluímos que a multifuncionalidade é uma noção estranha a rotina do assentado e, na baliza dos seus preceitos enquanto produtores/assentados encontra-se a lida no campo como algo necessário a sobrevivência e a resistência diária frente as práticas hegemônicas do capital (agronegócio).

Assim, para fins deste trabalho, entendemos a multifuncionalidade no Assentamento Rural Horto de Camaquã como uma possibilidade que pode orientar os preceitos e formas de atuação como assentamento e assentado ativo, participante e colaborativo da agenda nacional (e até mesmo mundial) de práticas sociais, culturais, ambientais e econômicas de ajustamento coletivo e comunitário. Estes ajustamentos, ao menos no nosso olhar devem contribuir para uma sociedade mais equânime do ponto de vista da preservação ambiental, segurança e autonomia alimentar, preservação do modo de vida rural e formas de gestão alternativa do território.

Deste modo, para além de promover as formas organizativas do/no assentamento, a noção aqui empregada, anuncia alternativas ao rural, através da (re)conexão das funções e possibilidades deste espaço, em sobremaneira, salutar ao Assentamento, dado suas restrições físicas e sociais já abordadas. Porquanto, o possível não prevê ao Assentamento o atraso e a marginalização, mas diametralmente prevê a possibilidade de se efetivar como espaço de vivência, sociabilidade, preservação, garantias e, sobretudo de reconstrução social. 


\section{REFERÊNCIAS}

BARBOSA, M. V. "Reforma Agrária" em terras públicas: um projeto que deu certo? In. MEDEIROS, L. et al. (Org.). Assentamentos Rurais: uma visão multidisciplinar. São Paulo: Editora da Universidade Estadual Paulista, 1994. p. 105-118.

BARBOSA, M. V; LEITE, S. Terras públicas: contradições de um governo democrático. Revista da Associação Brasileira de Reforma Agrária - ABRA, Campinas, n. 1, p. 4059, 1991.

BERGAMASCO, S. M. P. P; CARMO, M. S do. Reforma agrária dá certo? O (in)sucesso dos assentamentos de trabalhadores rurais. Revista da Associação Brasileira de Reforma Agrária - ABRA, Campinas, n. 1, p. 60-68, 1991.

BRUMER, A. et al. A exploração familiar no Brasil. In. LAMARCHE, H. A agricultura familiar. Campinas, SP: Editora da UNICAMP, 1993. p. 179-234.

CARDOSO, J. H; FLEXOR, G; MALUF, R. S. Multifuncionalidade da agricultura em áreas de assentamentos rurais: o caso de Abelardo Luz (SC). In. CARNEIRO, M. J; MALUF, R. S. (Org.). Para além da produção: Multifuncionalidade e Agricultura Familiar. Rio de Janeiro: MAUAD, 2003. p. 60-73.

CARNEIRO, M. J.; MALUF R. S. (Org.). Para além da produção: multifuncionalidade e agricultura familiar. Rio de Janeiro: MAUAD, 2003.

CARNEIRO, M. J; MALUF, R. S. Introdução. In. -

(Org.). Para além da produção: Multifuncionalidade e Agricultura Familiar. Rio de Janeiro: MAUAD, 2003. p. 17-27.

CARNEIRO, M. J. Juventude e novas mentalidade no cenário rural. In. CARNEIRO, M. J; CASTRO, E. G. Juventude Rural em perspectiva. Rio de Janeiro: Mauad X, 2007. p. 53-66.

Pluriatividade da agricultura no Brasil: uma reflexão crítica. In. SCHNEIDER, S. (Org.). A diversidade da agricultura familiar. Porto Alegre: Editora da UFRGS, 2006. p. $165-185$.

ITESP - Instituto de Terras do Estado de São Paulo. Disponível em: <http:// www.itesp.sp.gov.br/br/info/acoes/assentamentos.aspx> acessado em 23 de mar de 2018.

KUMMER, R; COLOGNESE, S. A. Juventude rural no Brasil: entre ficar e partir. Tempo da Ciência, v. 20, n. 39, 2013. Disponível em <http://e-revista.unioeste.br/index.php/ tempodaciencia/article/view/9817> Acesso em: 02 ago. de 2018.

MALAGODI, E. A questão agrária ontem e hoje. In. BERGAMASCO, S. M. P.P; OLIVEIRA, J. T. A. de; ESQUERDO, V. F de S. Assentamentos Rurais no século XXI: temas recorrentes. Campinas, SP: FEAGRI/UNICAMP; São Paulo: INCRA, 2011. p. 37-66.

MALAGODI, E; MARQUES, R. Para além de ficar ou sair: as estratégias de reprodução social dos jovens em assentamentos rurais. In. CARNEIRO, M. J; CASTRO, E. G. Juventude Rural em perspectiva. Rio de Janeiro: Mauad X, 2007. p. 197-214.

MALUF, R. S. A multifuncionalidade da agricultura na realidade rural brasileira. In. CARNEIRO, M. J; MALUF, R. S. (Org.). Para além da produção: Multifuncionalidade e Agricultura Familiar. Rio de Janeiro: MAUAD, 2003. p. 135-152.

PORTO-GONÇALVES, C. W. A geograficidade do social: uma contribuição para o debate metodológico para os estudos de conflitos e movimentos sociais na América Latina.

Revista eletrônica da Associação dos Geógrafos Brasileiros - Seção Três Lagoas - MS, v. 1, n. 3 - ano 3, maio de 2006. Disponível em: <http://seer.ufms.br/index.php/ RevAGB/article/view/1344> Acesso em: 22 jul. de 2018 
SÃO PAULO. Assembleia legislativa. Lei no 4.957, de 30 de dezembro de 1985. Dispõe sobre os planos públicos de valorização e aproveitamento dos recursos fundiários. São Paulo, SP, 1985. Disponível em <https://www.al.sp.gov.br/ repositorio/legislacao/lei/1985/lei-4957-30.12.1985.html> Acesso em: 2 ago. 2018.

VALVERDE, O. Reflexões sobre uma reforma agrária para o Brasil (Limites máximo e mínimo da propriedade da terra). In. MARIGHELLA, C. et. al A questão agrária no Brasil: textos dos anos sessenta. São Paulo: Ed. Brasil Debates, 1980. p. 58-64.

WANDERLEY, M. de N. B. Reforma agrária e modelo político de sociedade. In. BERGAMASCO, S. M. P. P; OLIVEIRA, J. T. A.; ESQUERDO, V. F. S. Assentamentos Rurais no século XXI: temas recorrentes. Campinas, SP: FEAGRI/UNICAMP; São Paulo: INCRA, 2011. p.21-24.

. Introdução. In. CARNEIRO, M. J; MALUF, R. S. (Org.) Para além da produção: Multifuncionalidade e Agricultura Familiar. Rio de Janeiro: MAUAD, 2003. pp. 9-16.

Recebido em outubro de 2018

Aceito em dezembro de 2018 